\title{
Comparing the effect of bioflocculant with synthetic polymers on enhancing granulation in UASB reactors for low-strength wastewater treatment
}

\author{
Jing-Song Wang, Yong-You Hu*, Chun-De Wu \\ School of Environmental Science and Engineering, South China University of Technology, Guangzhou 510640, P. R. China
}

\begin{abstract}
This study was aimed at introducing a novel bioflocculant to enhance anaerobic granulation in a UASB reactor for lowstrength synthetic wastewater and comparing the effect with synthetic polymers. A laboratory-scale study was undertaken to achieve this goal. Four identical UASB reactors were operated in parallel in the treatment of low-strength synthetic wastewater over $136 \mathrm{~d}$ at $35 \pm 1{ }^{\circ} \mathrm{C}$. One unit (labelled R1) was injected weekly with bioflocculant, a 2nd unit (labelled R2) was operated with the addition of acrylamide-chitosan graft copolymer, a 3rd unit (labelled R3) was operated with the addition of cationic polyacrylamide, and a 4th (labelled R4) served as a control without any polymer addition. The results showed that R1 was the most efficient, while R3 performed better than the other two reactors. The rates of granulation in R1, R2 and R3 were enhanced by $50 \%$ vs. $87 \%$ vs. $75 \%$ when compared with R4. Though bioflocculant addition was not the most effective way of developing large-size granules, it was demonstrated to be the least inhibitory in enhancing micro-organism multiplication and improving microbial metabolic activity. The volatile suspended solids to suspended solids ratio and the sludge methanogenic activity of the granular samples from R1 were higher than those of the other three reactors. When compared with the control reactor, polymer-added reactors performed better at the most organic loading rate as polymer addition resulted in a considerably higher degree of retention of biomass and lower solids washout from UASB reactors. Granulation was achieved in all four of the reactors, but the granules from polymer-enhanced reactors appeared earlier and were larger than those from the control reactor were.
\end{abstract}

Keywords: anaerobic granulation, bioflocculant, polymers, UASB

\begin{tabular}{ll}
\multicolumn{2}{l}{ Abbreviations } \\
ACGC & $\begin{array}{l}\text { acrylamide-chitosan graft copolymer } \\
\text { acrylic amide }\end{array}$ \\
AM & chemical oxygen demand \\
COD & extracellular polymers \\
ECPs & hydraulic retention time \\
HRT & organic loading rate \\
OLR & polyacrylamide \\
PAM & specific methanogenic activity \\
SMA & sludge retention time \\
SRT & suspended solids concentration \\
SS & sludge volume index \\
SVI & volatile fatty acid \\
VFA & volatile suspended solids concentration \\
VSS & upflow anaerobic sludge blanket
\end{tabular}

\section{Introduction}

In developing countries, a number of low-strength industrial wastewaters are frequently found. Moreover, many low-strength municipal wastewaters containing easily biodegradable matter are discharged without full treatment. In addition, in most urban areas the cost and availability of land are now a big problem. In an attempt to decrease water pollution in developing countries,

\footnotetext{
* To whom all correspondence should be addressed.

酉 +86-20-87114706; fax: +86-20-87111378;

e-mail:ppyyhu@scut.edu.cn

Received 5 July 2004; accepted in revised form 14 January 2005.
}

a treatment system should be promoted to fulfil the following requirements: Simple design, easy construction, low energy demand and high treatment efficiency. The anaerobic technology offers great potential in this regard. As a popular anaerobic technology, the UASB reactor has been widely used to treat many types of wastewater because it exhibits positive features such as high organic loadings, low energy demand, short hydraulic retention time, long sludge retention time and little sludge production. More than 900 UASB units are currently operating all over the world (Alves et al., 2000). Usually, they are used to treat medium- and high-strength wastewaters (Lettinga et al., 1993; Fang et al., 1995). They are seldom applied to treat lowstrength wastewater with COD concentration lower than 1500 to $2000 \mathrm{mg} / \ell$ because the development of granules in UASB reactors is very difficult when treating such wastewaters (Brito et al., 1997). To extend the application of the UASB reactor for low-strength wastewater treatment, research aimed at this kind of wastewater is necessary and significant, though few reports are found in the literature.

It is crucial to retain a high biomass concentration in a UASB reactor. In general, retention of biomass can be achieved by the principle of autoflocculation (i.e. self-immobilization of bacterial cells) leading to the formation of granules with good settling properties, and the formation of these granules is a key factor in the successful operation of a UASB reactor (Liu et al., 2002). As the anaerobic bacteria are slow-growing micro-organisms, a common problem in UASB operation is the long start-up period and the development of biogranules.

To overcome the limitations of long start-up periods and anaerobic granulation of UASB reactors, strategies for expediting granule formation are highly desirable (Liu et al., 2003; 


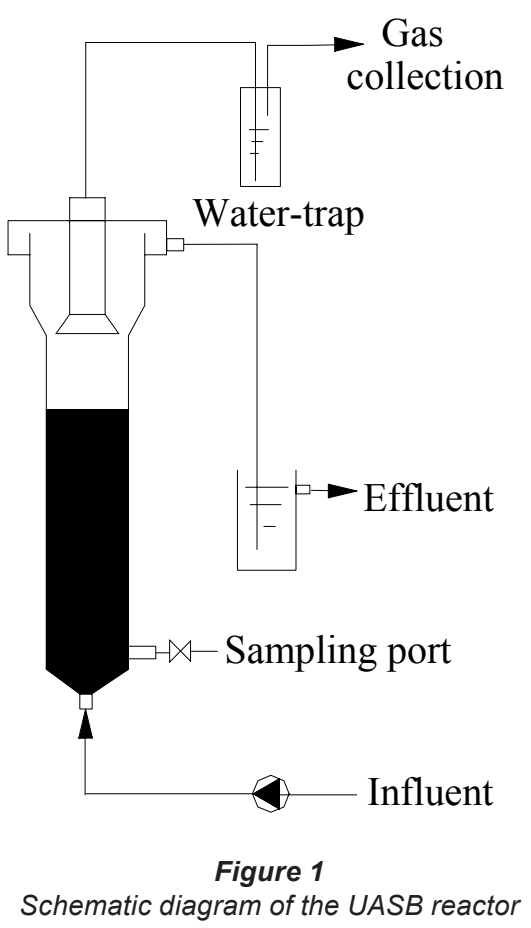

Hulshoff Pol et al., 2004). It has been shown that ECPs secreted by some anaerobic micro-organisms are associated with biological adhesion and aggregation processes (Costerton et al., 1981; Cammarota and Sant' Anna, 1998). It is being hypothesized that ECPs in granules bridge two neighbouring bacterial cells physically as well as binding them to other inert particulate matter, and settle out as floc aggregates (Ross, 1984; Shen et al., 1993; Schmidt and Ahring, 1994). It appears that ECPs play an important role in anaerobic granulation. Similarly, other polymers can also promote bacterial agglomeration and could be introduced to enhance anaerobic granulation in UASB reactors. Polymers are mainly used either to immobilize the anaerobic sludge within gel beads or to reinforce the strength of the already existing granules by coating the granule surfaces with a thin layer of polymer (Araki et al., 1987; Chigusa et al., 1991). It was found that supplementation with chitosan significantly enhanced the formation of anaerobic granules in the USAB-like reactors; the granulation rate in the chitosan-containing reactor was 2.5 -fold higher than that in the control reactor without supplementation of the polymer, while the specific activity of methane production almost remained unchanged in both reactors (El-Mamouni et al., 1998). Kalogo et al. (2001) used a water extract of Moringa oleifera seeds to enhance the start-up of a UASB reactor treating domestic wastewater, and the dosage in the feed promoted the aggregation of coccoid bacteria and growth of microbial nuclei, which are precursors of anaerobic granulation. Recently, Show et al. (2004) used cationic polymers with a concentration of $80 \mathrm{mg} / \ell$ in a UASB reactor to decrease start-up time by $43 \%$ compared to the control reactor without polymer addition.

As described above, synthetic polymers are demonstrated to promote anaerobic granulation. However, they have negative effects on micro-organisms such as the polymers' inhibitory effects on substrate transfer to granules and the remnant monomer's toxicity on micro-organisms. Compared to synthetic polymers, bioflocculants have two obvious advantages: Safety to the environment and ease of biodegradation (Salehizadeh, 2001).

\begin{tabular}{|l|c|c|c|}
\hline \multicolumn{4}{|c|}{ TABLE 1 } \\
Composition of the synthetic wastewater \\
\hline $\begin{array}{l}\text { Constitu- } \\
\text { ents }\end{array}$ & $\begin{array}{c}\text { Concentra- } \\
\text { tion (mg/l) }\end{array}$ & $\begin{array}{c}\text { Constitu- } \\
\text { ents }\end{array}$ & $\begin{array}{c}\text { Concentra- } \\
\text { tion (mg/l) }\end{array}$ \\
\hline $\mathrm{Glucose}_{\mathrm{NaHCO}}$ & 650 & $\mathrm{KH}_{2} \mathrm{PO}_{4}$ & 5 \\
$\mathrm{NaHC}_{3}$ & 550 & $\mathrm{~K}_{2} \mathrm{HPO}_{4}$ & 6 \\
$\mathrm{CaCl}_{2}$ & 30 & $\left(\mathrm{NH}_{4}\right)_{2} \mathrm{MoO}_{4}$ & 0.05 \\
$\mathrm{MgSO}_{4}$ & 25 & $\mathrm{CoCl}_{2}$ & 0.6 \\
$\mathrm{FeCl}_{2}$ & 5 & $\mathrm{NiCl}_{2}$ & 0.5 \\
$\mathrm{NH}_{4} \mathrm{Cl}$ & 30 & $\mathrm{H}_{3} \mathrm{BO}_{3}$ & 0.5 \\
Yeast extract & 40 & & \\
\hline
\end{tabular}

\begin{tabular}{|l|c|c|}
\hline \multicolumn{3}{|c|}{ TABLE 2 } \\
\hline SS $\mathbf{( m g / l )}$ & $\begin{array}{c}\text { VSS } \\
(\mathbf{m g} / \mathbf{l})\end{array}$ & VSS/SS \\
\hline 59.53 & 17.43 & 0.29 \\
\hline SVI $(\mathrm{ml} / \mathrm{g})$ & $\begin{array}{c}\mathrm{SMA} \\
\left(\mathrm{g} \mathrm{COD}-\mathrm{CH}_{4} / \mathrm{g} \text { VSS.d }\right)\end{array}$ & $\begin{array}{c}\text { Particle diameter } \\
(\mathrm{mm})\end{array}$ \\
\hline 20.92 & 0.088 & $<0.15$ \\
\hline
\end{tabular}

Based on previous research that polymers or flocculants could improve anaerobic granulation, the assumption is that bioflocculants might also enhance the process. However, few reports on bioflocculant addition to enhance anaerobic granulation have been published.

This study aimed at introducing a novel bioflocculant to enhance anaerobic granulation in UASB reactors for low-strength synthetic wastewater treatment and comparing the effect with synthetic polymers (ACGC and cationic PAM).

\section{Experimental}

\section{Reactor systems}

Experiments were performed in parallel in four identical reactors $(5.03 \ell)$ for $136 \mathrm{~d}$ at $35 \pm 1^{\circ} \mathrm{C}$. Sample sludge was taken from the sampling port on the bottom of the reactor. The schematic diagram is shown in Fig. 1. Reactor 1 (R1) was started up with the addition of bioflocculant, Reactor 2 (R2) was started up with addition of ACGC, Reactor 3 (R3) was started up with addition of cationic PAM, and Reactor 4 (R4) without addition of flocculants served as the control.

\section{Feed}

The feed in this study was synthetic wastewater. Its detailed composition is shown in Table 1. The COD in the influent ranged from $550 \mathrm{mg} / \ell$ to $650 \mathrm{mg} / \ell$ throughout the study. The COD: $\mathrm{N}$ : $\mathrm{P}$ ratio in the wastewater was 300:5:1. The buffering capacity was maintained by addition of sodium bicarbonate. Ferrous ion, magnesium ion, calcium ion and other micro-nutrients were also added.

\section{Seed sludge}

The seeding inoculum was obtained from municipal anaerobic digested sludge and was screened through a $0.15 \mathrm{~mm}$ sieve to remove the big debris before seeding. Its detailed properties are shown in Table 2. Each reactor was seeded with $2.5 \ell$ of sludge with biomass content of $8.58 \mathrm{~g} \mathrm{VSS} / \ell$. 
Figure 2

(a) COD removal efficiencies of all the four reactors; (b) Effluent SS of all the four reactors; (c) v; (d) HRT and $O L R$ of all the four reactors
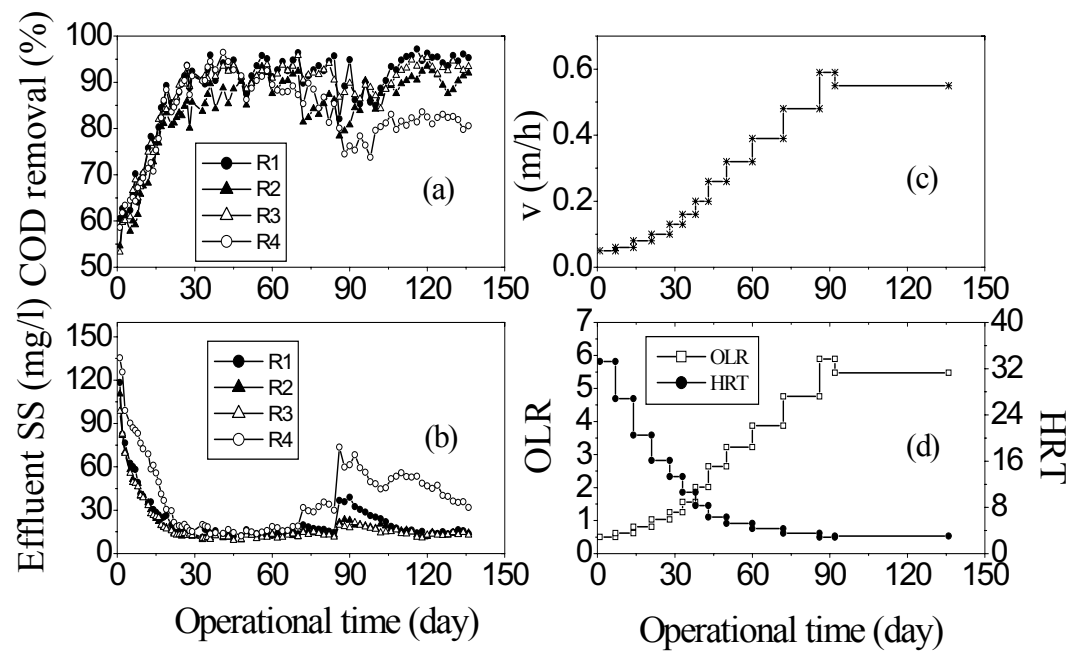

\section{Analytical methods}

COD and solids were measured according to Standard Methods (1992). The SMA of sludge samples taken from the bottom of the reactors was measured in a $400 \mathrm{~m} \ell$ serum bottle at $35 \pm 1^{\circ} \mathrm{C}$ under anaerobic conditions.

For estimating the size distribution, the sludge samples taken from the bottom of the reactors were classified into 5 fractions using sieves with different openings $(0.15,0.45,0.7,1.0 \mathrm{~mm}, 2.0$ $\mathrm{mm})$. The particles were gently submerged in water and agitated to let the small particles pass through each sieve.

\section{Addition of bioflocculant and synthetic polymers}

The bioflocculant named MBF21 in this study was prepared in our laboratory. Polysaccharides are its effective component; these are exobacterial substances secreted by the bacterium Penicillium cyclopium screened from the activated sludge (Chen and $\mathrm{Hu}, 2004)$. The concentration of polysaccharides in this bioflocculant solution is $3.5 \mathrm{mg} / \ell$ and its average molecular mass is 1000000 . Because the bioflocculant is negatively charged, calcium ion was added to neutralize the negative charge of the sludge surface before the bioflocculant was added to R1. ACGC was synthesized in our laboratory with average molecular mass being 3500 000. It was added to R2. Cationic PAM, produced in the USA with an average molecular mass of 8000000 , was added to R3. The dose was assessed by measuring both the maximum turbidity removal efficiency and the minimum SVI of the flocculated biomass using the Jar test method (El-Mamouni et al., 1997). As a result, the optimal dose of calcium ion and bioflocculant solution was $12 \mathrm{mg} / \mathrm{g}$ SS and $8 \mathrm{~m} \ell / \mathrm{g}$ SS respectively; optimal dose of ACGC was $3 \mathrm{mg} / \mathrm{g} \mathrm{SS}$; optimal dose of cationic PAM was $2 \mathrm{mg} / \mathrm{g}$ SS. Bioflocculant and synthetic polymers were injected weekly. A total of 12 injections were carried out during the course of the experiments.

\section{Results and discussions}

\section{Reactor performance}

All four UASB reactors started out with an initial OLR of $0.5 \mathrm{~g}$ $\mathrm{COD} / \ell \cdot \mathrm{d}, \mathrm{HRT}$ of $33.2 \mathrm{~h}$ and an upflow liquid velocity of 0.05 $\mathrm{m} / \mathrm{h}$. The reactors' performance, in terms of COD removal and effluent SS, is illustrated in Fig. 2. As the $\mathrm{pH}$ value in the feed was adjusted from 6.5 to 7.2 , in the effluent it changed from 7.0 to 7.6 in all four reactors, a little higher than that in the feed. This was because the VFA in the feed was transformed to methane and carbon dioxide, with a subsequent increase in $\mathrm{pH}$ value in the effluent.

As shown in Fig. 2 (a), because the micro-organisms' activity and concentration were low, the COD removal efficiencies of all four reactors were low during the first $10 \mathrm{~d}$. R2 had the lowest COD removal efficiency because anaerobic micro-organisms were not fit to ACGC yet at this stage. As the experiments proceeded in time, the COD removal efficiencies of all four reactors kept increasing. As polymers promoted bacterial agglomeration, more biomass was retained in polymer-enhanced reactors. Though the COD removal efficiency of all four reactors was similar at $90 \mathrm{~d}$ after start-up, it was evident that the COD removal efficiency of polymer-enhanced reactors was higher than that of the control reactor during the remaining 46d. However, due to the negative effect of ACGC on micro-organisms, the COD removal efficiency of R2 was still lower than that of R4 before reaching an OLR of $3.87 \mathrm{~g} \mathrm{COD} / \ell \cdot \mathrm{d}$ with an HRT of $4.3 \mathrm{~h}$ (Fig. $2 \mathrm{~d}), \mathrm{R} 4$ being inferior to the other three reactors thereafter. The COD removal efficiency of R1 was higher than that of R2 and R3 at all the OLRs throughout the experiments, which indicated that bioflocculant had a lower negative effect on anaerobic micro-organisms than ACGC and cationic PAM, i.e., the polymeric gel around cells formed by the bioflocculant did not inhibit substrate diffusion into and out of the microbial mass as much as ACGC and cationic PAM did. As the OLR reached $5.89 \mathrm{~g} \mathrm{COD} / \ell \cdot \mathrm{d}$ and HRT shortened to $2.8 \mathrm{~h}$, the COD removal efficiencies of all four reactors decreased suddenly, which implied that the substrate in the reactors could not be fully degraded at such short HRT. While adjusting the HRT to $3 \mathrm{~h}$, the COD removal efficiencies recovered immediately. At this stage, the COD removal efficiencies of polymer-enhanced reactors were higher than that of R4. This result is due to the accumulation of micro-organisms by polymers, while more micro-organisms could transform more substrate to methane and carbon dioxide.

The effluent SS of all the four reactors is shown in Fig. 2(b). During the first $15 \mathrm{~d}$, the effluent SS concentration of all the four reactors was high due to the seed sludges' inferior settleability. The fact that more biomass discharged from R4 than the other three reactors implied that polymers caused more dispersed sludge coagulation. While the experiments proceeded, granules formed and developed in all four reactors, the biomass settleability improved, less biomass was washed out from the reactors, but more biomass was washed out from R4. The efflu- 


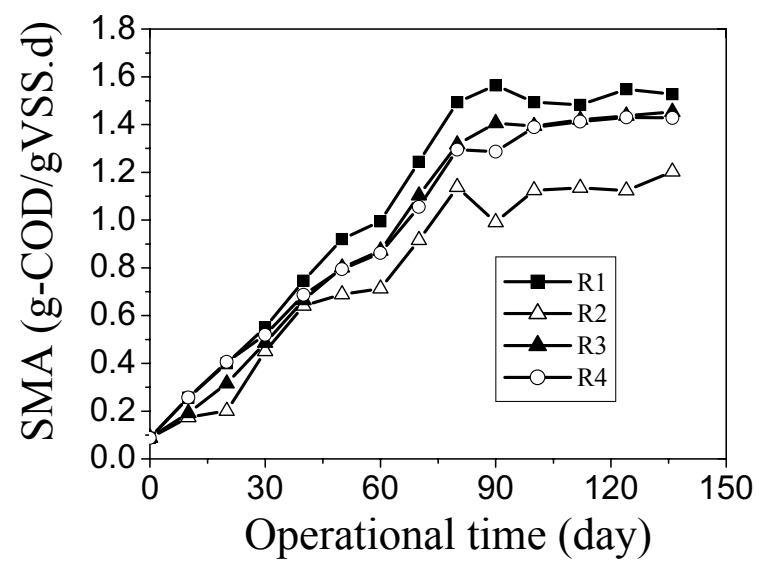

Figure 3

SMA of granules from different reactor

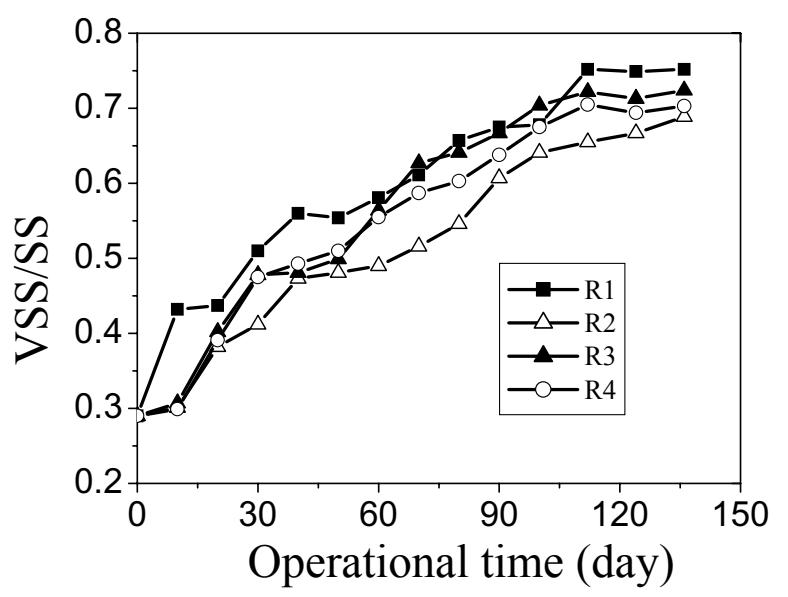

Figure 4

Ratio of VSS to SS of granules from different reactor

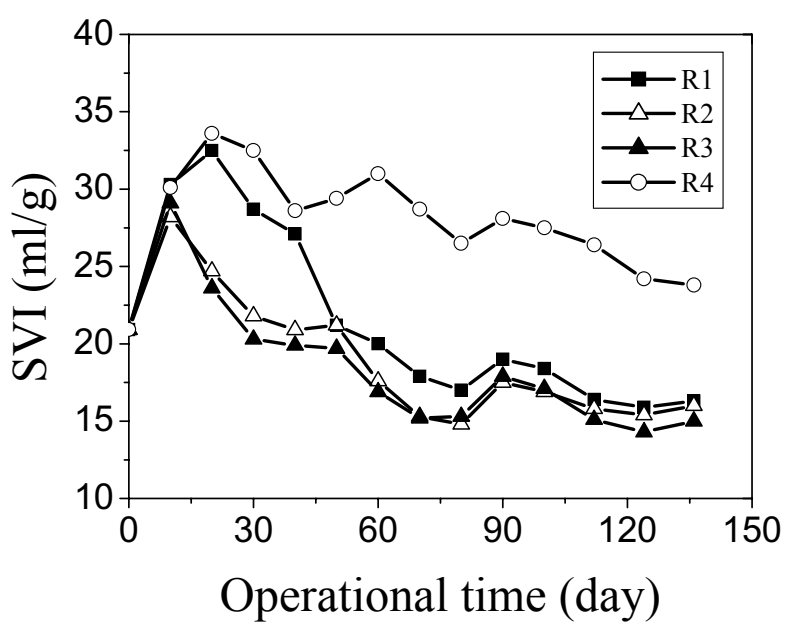

Figure 5

SVI of granular samples from different reactor

ent SS increased in all four reactors with OLR achieving 5.89 $\mathrm{g} \mathrm{COD} / \ell \cdot \mathrm{d}$, HRT decreasing to $2.8 \mathrm{~h}$ and the upflow liquid velocity increasing to $0.59 \mathrm{~m} / \mathrm{h}$. This indicated that $0.59 \mathrm{~m} / \mathrm{h}$ of upflow liquid velocity caused more biomass out of the reactors (Fig. 2c). This might be the result of loose granules developing in the reactors operating at low-strength wastewater.

\section{Sludge characteristics}

The sludge characteristics could be judged by the metabolic activities, sludge settleability and the total biomass in the sludge. These can be expressed in terms of SMA, SVI and ratios of VSS to SS, respectively.

As shown in Fig. 3 and Fig. 2 (d), the SMAs of the sludge in $\mathrm{R} 1, \mathrm{R} 2, \mathrm{R} 3$ and $\mathrm{R} 4$ at OLR of $1.25 \mathrm{~g} \mathrm{COD} / \ell \cdot \mathrm{d}$ were $0.551,0.451$, 0.486 and $0.519 \mathrm{~g} \mathrm{COD}-\mathrm{CH}_{4} / \mathrm{g} \mathrm{VSS} \cdot \mathrm{d}$, respectively. After OLR reached $5.47 \mathrm{~g} \mathrm{COD} / \ell \cdot \mathrm{d}$, the SMA of sludge in R1, R2, R3 and R4 were $1.494,1.138,1.317$ and $1.295 \mathrm{~g} \mathrm{COD}-\mathrm{CH}_{4} / \mathrm{g}$ VSS·d, respectively. At the end of the experiments, the SMA of sludge in R1,

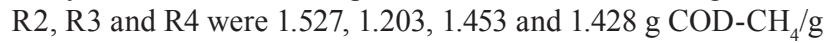
VSS·d, respectively. It was evident that the SMA of R1 sludge was highest at all OLRs while that of R2 was lowest throughout the experiments. The highest SMA values in R1 indicated that bioflocculant addition enhanced the sludge methanogenic activities more than synthetic polymers. This result further demonstrated that bioflocculant, a natural polymer, had less negative effect on anaerobic micro-organisms than synthetic polymers, especially ACGC. Corresponding results were reported by ElMamouni (El-Mamouni, 1998).

Figure 4 shows the amounts of biomass in the sludge. As anaerobic bacteria accumulated and multiplied in the reactors, the VSS/SS of the sludge in all four reactors increased. Similar to SMA, the VSS/SS of the sludge in R1 was highest while that in R2 was lowest at each OLR. This indicated that more microorganisms accumulated and multiplied in R1 than in the other three reactors. As the experiments ended, the VSS/SS of the sludge in R1, R2, R3 and R4 was $0.752,0.689,0.724$ and 0.703 , respectively.

As the seed sludge was taken from digested anaerobic sludge, high SS content resulted in low SVI values; when microorganisms multiplied in the reactors, the VSS/SS of the sludge increased (Fig. 4). The sludge first became loose, the SVI of the sludge in all four reactors increased, then, because of the effects of improved bacterial adhesion, coagulation caused by the addition of polymers or autoflocculation, the SVI of the sludge in all four reactors decreased. As shown in Fig. 5, from day 30 to day 50 , the SVI of the sludge in R2 and R3 decreased faster than that in R1. This indicated that synthetic polymers proved to be superior over the bioflocculant in improving sludge settleability. As the synthetic polymers applied in this study are cationic polymers, they could not only neutralize the negative charge of the bacteria but could also bridge the gap between cells simultaneously. While the bioflocculant used in this study is an anion polymer and has a lower molecular mass than synthetic polymers, it could not coagulate dispersed sludge to the same good effect as synthetic polymers. These resulted in lower SVI values of the sludge in R2 and R3 than that in R1. However, the SVI of sludge in R1 was much lower than that in the control reactor, R4, indicating that bioflocculant improved the sludge settleability when compared to the control reactor. At the end of the experiments, the SVIs of the sludges in R1, R2, R3 and R4 were 16.3, $16,15.0$ and $23.8 \mathrm{ml} / \mathrm{g}$, respectively. When compared to $\mathrm{R} 4$, the SVIs of the sludges in R1, R2 and R3 were $31.5 \%, 32.7 \%$ and $37.0 \%$, respectively, lower than that in R4. Enhanced granule settleability indicated by the SVI value could be due to improved bacterial adhesion caused by addition of polymers. The resulting chain-like structure may lead to a complex network structure for enhanced bacterial aggregation (Yoda et al., 1989; Wirtz et al., 1996).

Though synthetic polymers were superior to bioflocculant in respect of agglomerating anaerobic micro-organisms, they 

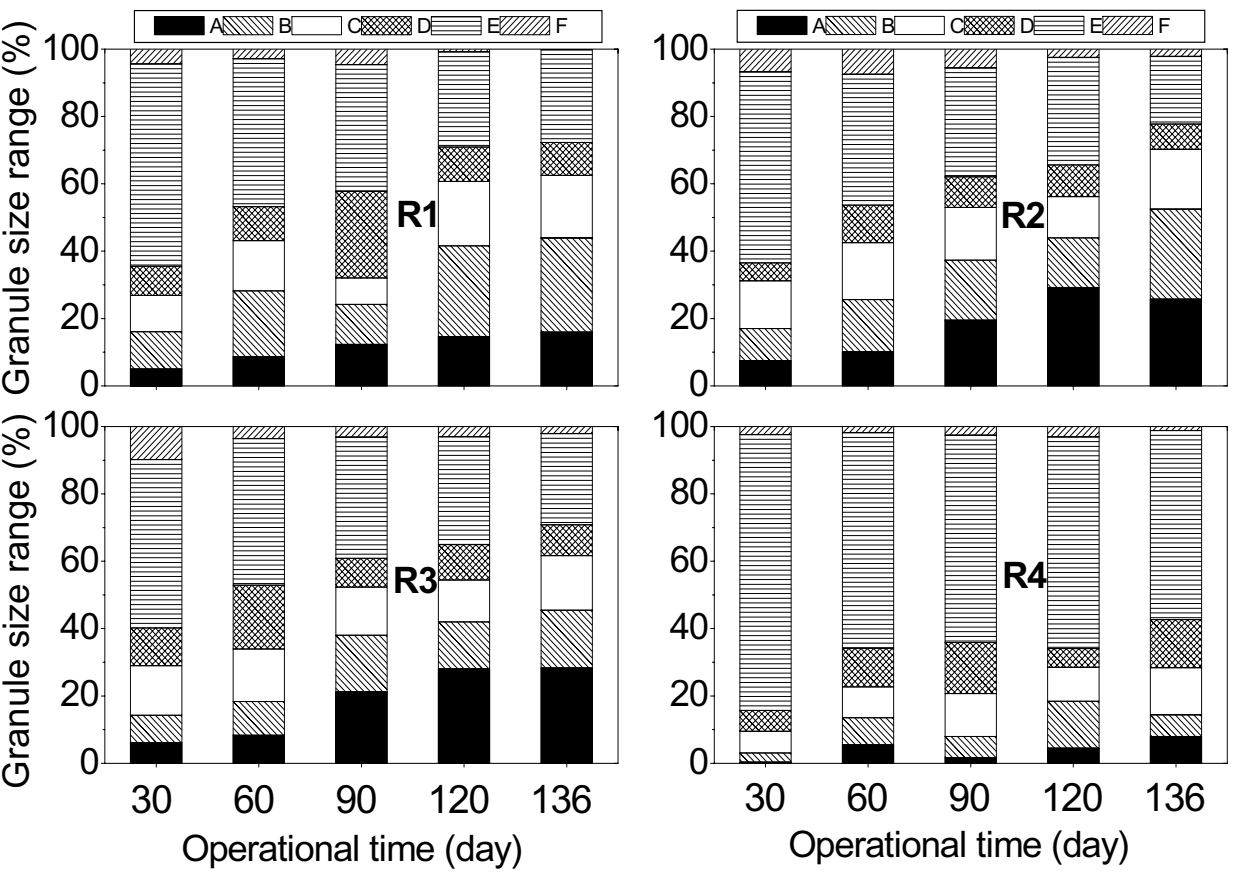

Size distributions (by weight) of granules taken from the bottom sampling point in each reactor (A) $>2.0 \mathrm{~mm} ;(B) 1.0<d<2.0$ $\mathrm{mm}$; (C) $0.7<d<1.0 \mathrm{~mm}$; (D) $0.45<d<0.7 \mathrm{~mm}$; (E) 0.15 $<d<0.45 \mathrm{~mm} ;(F)<0.15 \mathrm{~mm}$

had a more negative effect on enhancement of SMA and microorganism multiplication suggested by sludge characteristics (Fig. 3 to Fig. 5). This might be the result of the layer of polymeric gel which inhibited substrate transference or toxicity of the residual monomer accumulation on anaerobic bacteria.

\section{Development of granules}

Figure 6 illustrates granule distribution in all four reactors. As the experiments proceeded, granule size increased in all the reactors. On day 30 in all four reactors, the granules of size of 0.15 to $0.45 \mathrm{~mm}$ are clearly predominant, indicating that granules developed slowly during this period. In polymer-enhanced reactors, i.e. R1, R2 and R3, the distribution is more scattered than that in the control reactor R4 because the polymers promoted granule formation by allowing aggregates to form and achieve a bigger size.

In terms of distribution of granules, granules developed faster and became larger in polymer-added reactors than those in the control reactor did. From start-up of the reactors to day 100 , with polymers injected during this period, the granulation rate in $\mathrm{R} 1, \mathrm{R} 2, \mathrm{R} 3$ and $\mathrm{R} 4$ was 7.72 ( $\mathrm{SD}=1.21), 9.61(\mathrm{SD}=1.44), 9.83$ $(\mathrm{SD}=1.47)$ and $4.83(\mathrm{SD}=0.78) \mu \mathrm{m} / \mathrm{d}$, respectively. Throughout the experiments, average granulation rate in R1, R2, R3 and R4 was $6.43(\mathrm{SD}=1.27), 8.05(\mathrm{SD}=1.46), 7.54(\mathrm{SD}=1.53)$ and 4.30 $(\mathrm{SD}=0.82) \mu \mathrm{m} / \mathrm{d}$, respectively. Compared to the control reactor (R4), the granulation rates in R1, R2 and R3 were $49.5 \%, 87.2 \%$ and $75.3 \%$, respectively, higher than that in R4. These data demonstrated that polymers, both bioflocculant and synthetic polymers, enhanced granule development in UASB reactors. However, granular development cannot be judged as "better granular" only in terms of its "large size" (Show et al., 2004). As discussed before, granular characteristics should be considered in terms of metabolic activities, settleability and multiplication of microorganisms.

\section{Conclusions}

The results of this study showed that the incorporation of biofloc-

culant or synthetic polymers significantly enhanced anaerobic granulation in UASB reactors for low-strength wastewater treatment. When compared to the control reactor, the granulation rate in the bioflocculant-enhanced reactor, the ACGC-enhanced reactor and the cationic PAM-enhanced reactor increased by $49.5 \%, 87.2 \%$ and $75.3 \%$, respectively.

The use of bioflocculant and cationic PAM improved sludge granulation and sludge characteristics, and these two polymer-enhanced reactors performed better than the control reactor throughout the experiments. The ACGC-enhanced reactor showed worse reactor performance before reaching an OLR of $3.87 \mathrm{~g} \mathrm{COD} / \ell \cdot \mathrm{d}$. The SMA and VSS/SS sludge values in this reactor were lower than those in the control reactor at each OLR. This indicated that ACGC had some negative effect on anaerobic microbes. Similarly, cationic PAM also exhibited a negative effect on anaerobic microbes when compared with bioflocculant, as demonstrated by SMA and VSS/SS values in Figs. 3 and 4 . The superiority of natural polymers over synthetic ones in flocculating cell suspensions has already been reported elsewhere (Hughes et al., 1990; Ndabigengesere et al., 1995; El-Mamouni et al., 1998).

Granules must not be judged in terms of "large size" only; their other characteristics should be considered as well. As the results of these experiments show, ACGC had a more positive effect on the development of large-size granules than bioflocculant, but the former had a more negative effect on SMA and VSS/SS of sludge than the latter. Therefore the conclusion can be drawn that bioflocculant is more suitable for enhancing anaerobic granulation than ACGC. Cationic PAM had a less negative effect on sludge characteristics than ACGC, but a more negative effect than the bioflocculant. At the same time, it was more effective in developing large granules than a bioflocculant. Based on this result, cationic PAM could also be used to enhance anaerobic granulation.

\section{Acknowledgements}

This study was supported by the National Natural Science Fund, PR China (Project No 50378039). 


\section{References}

ALVES M, CAVALEIRO AJ, FERREIRA EC, AMARAL AL, MOTA M, DA MOTTA M, VIVIER H and PONS MN (2000) Characterization by image analysis of anaerobic sludge under shock conditions. Water Sci. Technol. 41 (12) 207-514.

BRITO AG, RODRIGUES AC and MELO LF (1997) Granulation during the start-up of a UASB reactor used in the treatment of lowstrength wastewaters. Biotechnol. Lett. 9 (4) 363-367.

CAMMAROTA MC and SANT' ANNA GL (1998) Metabolic blocking of exopolysaccharides synthesis: effects on microbial adhesion and biofilm accumulation. Biotechnol. Lett. 20 1-4.

CHEN W and HU YY (2004) Research on the characteristics of four bioflocculants. Fine Chem. 21 (2) 141-152.

COSTERTON JW, IRVIN RT and CHENG KJ (1981) The bacterial glycocalyx in nature and disease. Ann. Rev. Microbiol. 35 299-324.

EL-MAMOUNI R, LEDUC R and GUIOT SR (1997) Influence of the starting microbial nucleus type on the anaerobic granulation dynamics. Appl. Microbiol. Biotechnol. 47 (2) 189-194.

EL-MAMOUNI R, LEDUC R and GUIOT SR (1998) Influence of synthetic and natural polymers on the anaerobic granulation process. Water Sci.Technol. 38 (8-9) 341-347.

FANG HHP, CHUI HK and LI YY (1995) Anaerobic degradation of butyrate in a UASB reactor. Bioresour.Technol. 51 (1) 75-81.

HIGUSA K and MATSUMOTO J (1991) Gel-reinforced self-granulated sludge. Japanese Patent 3,254,895.

HUGHES J, RAMSDEN DK and SYMES KC (1990) The flocculation of bacteria using cationic synthetic flocculants and chitosan. Bioresour. Technol. 4 55-60.

HUSLSHOFF POL LW, DE CASTRO LOPES SI, LETTINGA G and LENS PNL (2004) Anaerobic sludge granulation Water Res. 38 (6) 1376-1389.

KALOGO Y, SEKA AM and VERSTRAETE W (2001) Enhancing the start-up of a UASB reactor treating domestic wastewater by adding a water extract of Moringa oleifera seeds. Appl. Microbiol. Biotechnol. 55 (5) 644-651.

LETTINGA G, DE MAN A, VAN DER LAST ARM, VAN BUUREN JCL, FRIJNS J, WIEGANT W and VAN KNIPPENBERG K (1993)
Anaerobic treatment of domestic sewage and wastewater. Water Sci. Technol. 27 (9) 67-73.

LIU Y, XU HL, SHOW KY and TAY JH (2002) Anaerobic granulation technology for wastewater treatment. World J. Microbiol. Biotechnol. 18 99-113.

LIU Y, XU HL, YANG SF and TAY JH (2003) Mechanisms and models for anaerobic granulation in upflow anaerobic sludge blanket reactor. Water Res. 37 661-673.

NDABIGENGESERE A, NARASIAH KS and TALDOT BG (1995) Active agents and mechanism of coagulation of turbid water using Moringa oleifera. Water Res. 29 703-710.

RAKI N and KAWAI N (1987) Surface immobilized anaerobic bacteria granule and treatments of wastewater. Japanese Patent 62, 279, 887.

ROSS WR (1984) The phenomenon of sludge pelletization in the anaerobic treatment of a maize processing waste. Water SA 10 197-204.

SALEHIZADEH H and SHOJAOSADATI SA (2001) Extracellular biopolymeric flocculants: Recent trends and biotechnology importance. Biotechnol. 19 (5) 371-385.

SCHMIDTJE and AHRING BK (1994) Extracellular polymers in granular sludge from different upflow anaerobic sludge blanket (UASB) reactors. Appl. Microbiol. Biotechnol. 42 457-462.

SHEN CF, KOSARIC N and BLASZCZYK R (1993) The effect of selected heavy metals ( $\mathrm{Ni}, \mathrm{Co}$ and $\mathrm{Fe}$ ) on anaerobic granules and their extracellular polymeric substances (EPS). Water Res. 27 25-33

SHOW KY, Wang Y, FOONG SF and TAY JH (2004) Accelerated startup and enhanced granulation in upflow anaerobic sludge blanket reactors. Water Res. 38 (9) 2293-2304.

STANDARD METHODS (1992) Standard Methods for the Examination of Water and Wastewater (18th edn.). American Public Health Association. New York, USA.

WIRTZ RA and DAGUE RR (1996) Enhancement of granulation and start-up in the anaerobic sequencing batch reactor. Water Environ. Res. 68 (5) 883-892.

YODA M, KITAGAWA M and MIYAJI Y (1989) Granular sludge formation in the anaerobic expanded micro-carrier bed process. Water Sci. Technol. 21 109-120. 